\title{
O DISCURSO PROFÉTICO: CONDIÇÕES DE FORMAÇÃO DAS RELAÇÕES HEGEMÔNICAS ENTRE O POVO JUDEU, A PARTIR DE ENUNCIAÇÕES DO VELHO TESTAMENTO
}

\author{
Ana Zandwais
}

RESUMO: Theory of Enunciation researches can explain questions concerning the roles of subjectivity in language, as well as descontinuities found between discoursive and linguistic objects. In this paper we analyse the formative conditions of the Jewish social hegemony, by investigating an historical discourse taken from the Old Testament: a profecy against the king Jeroboam (Book of the Kings). Considering the intersection of voices in statements of discourse and the cathegories of distance, opacity, tension and modality, we try to describe how the effects of senses produced by that voices can represent relations of power in the ancient Jewish society.

PALAVRAS-CHAVE: profecia, opacidade, tensão, convenções sociais e religiosas, fala e silêncio.

\section{INTRODUÇÃO}

O presente estudo, que toma como referenciais teóricos básicos os pressupostos de Enunciação de Dubois (1969), Courdesses (1971) e Ducrot (1987), propõe-se a investigar, a partir de formulações enunciativas inscritas em discursos do Velho Testamento, como são representadas as relações fundadoras das práticas sociais entre o povo judaico, tomando como objeto de análise uma profecia dirigida ao rei Jeroboão pelo profeta Aías ${ }^{1}$.

\footnotetext{
Ana Zandwais é professora no Instituto de Letras da UFRGS

${ }^{1}$ Sob o aspecto histórico de suas condições de produção, os discursos proféticos de Aías ocorreram: a) durante o reinado de Salomão, prevendo a queda deste e a missão de Jeroboão como governante de dez tribos de Israel; b) durante o reinado de Jeroboão, prevendo sua destruição.
} 


\section{ALGUNS PRESSUPOSTOS SOBRE A NATUREZA E O FUNCIONAMENTO DO OBJETO DISCURSIVO}

As relações estabelecidas entre enunciação e enunciado, embora tenham sido institucionalizadas em práticas de análises de narrativas, através de estudos realizados pelo Círculo Lingüístico de Praga (1929) e por um pequeno grupo de intelectuais, denominado Círculo de Bakhtin, não lograram êxito em caracterizar a sobredeterminação dos processos enunciativos em relação a seus produtos; isto é, os enunciados.

De acordo com Dubois (1969) e Yaguello (1986), as práticas de análises discursivas por essas duas correntes de teóricos podem ser caracterizadas respectivamente por: a) confinar os estudos dos processos enunciativos às práticas de análises dos enunciados (estruturas); h) não obter reconhecimento, em face da apresentação de concepções antagônicas aos pressupostos ${ }^{2}$ vigentes entre os formalistas russos e tchecos.

Assim, é a partir dos estudos de Benveniste (1989) que as relações entre sujeito e objeto, nos domínios da linguagem, são caracterizadas por vínculos estabelecidos entre enunciado e enunciação, enquanto formas de representação das propriedades de interdependência entre processo e produto; isto é, entre o dizer e o dito.

É, pois, com base em noções de subjetividade e intersubjetividade que Benveniste introduz uma perspectiva de redefinição da natureza do objeto téoricometodológico de investigações da Lingüística, já que, segundo o autor, o lugar do sujeito somente é assegurado pelo exercício da linguagem na relação com o outro, e pelo processo individual de apropriação da língua para a expressão única, irrepetível e histórica da subjetividade do eu.

Assim, é pela expressão da subjetividade de um ego na relação com outro ego que Benveniste expõe sua tese de que a propriedade de intersubjetividade: a) é caracterizada pela reversibilidade de papéis entre os sujeitos (eu e $t u)$; b) é determinada por uma exterioridade constitutiva da materialidade das significações na linguagem.

Já Courdesses (1971), com base em concepções de Dubois ${ }^{3}$ (1969), define a enunciação como a "atitude do locutor diante de seu próprio enunciado e da situação". Assim, o processo de enunciação passa a ser descrito a partir de relações de identificação, maiores ou menores, assumidas pelo enunciador em relação a seus interlocutores, e frente a seus enunciados, de modo que as condições de exclusão e inclusão dos interlocutores nos enunciados são determinadas tanto pela natureza dos acontecimentos discursivos como pelos tipos de índices enunciativos que

\footnotetext{
${ }^{2}$ Referimo-nos às tendências formalistas e sociológicas dominantes no campo dos estudos sobre a linguagem durante a década de 20.

${ }^{3}$ A partir de leituras críticas sobre concepções de enunciação/enunciado adotadas por gerativistas e estruturalistas, Dubois (1969) utiliza os conceitos de distância, opacidade, tensão e modalização com o objetivo de caracterizar diferenças de funcionamento entre operadores discursivos e lingüísticos.
}

80 
representam, na materialidade enunciativa, os efeitos de sentidos produzidos em cada instância de discurso.

Observando, em primeiro lugar, que o comportamento dos índices enunciativos constitui uma ordem de funcionamento distinta do comportamento dos índices lingüísticos, a autora inscreve os últimos nos primeiros, caracterizando a heterogeneidade de funcionamento dos índices lingüísticos, com base nos tipos de relações intersubjetivas produzidas em cada instância de produção de discurso. Portanto, é a partir de tais decisões que podem ser reconhecidas as relações nãosimétricas entre as categorias de análise dos objetos lingüístico e discursivo.

Considerando também que toda instância discursiva constitui-se, de forma dialética, de elementos invariantes e de variáveis, a autora caracteriza:

a) como invariantes, as realidades sociohistóricas que se apresentam na emergência das condições de produção dos discursos; b) como variáveis, os tipos de relações intersubjetivas que colocam em evidência as posições assumidas pelos enunciadores diante da emergência do momento histórico de produção da enunciação.

A partir de um estudo sobre o funcionamento de índices enunciativos ${ }^{4}$, proposto inicialmente por Dubois, Courdesses coloca em prática algumas relações de intersecção entre operadores discursivos e lingüísticos, que serão tomados como objetos da discussão a seguir.

a) Os conceitos de distância/proximidade representam atitudes do enunciador frente a seus enunciados, na proporção em que esse assume, em maior ou menor escala, a responsabilidade do dito. Assim, quanto maior a proximidade do enunciador em face de seus enunciados, maior o grau de transparência do processo de enunciação. Por outro lado, quanto mais expressiva a distância, maior o apagamento do processo de enunciação no conteúdo dos enunciados.

b) Os conceitos de transparência/opacidade representam os diferentes graus de polissemia enunciativa que configuram, nas estruturas dos enunciados, tanto as condições de produção das relações de intersubjetividade, como as formas de aproximação/distanciamento, através das quais o enunciador se coloca diante de seus interlocutores, imputando a si mesmo ou a outro a responsabilidade de determinar os efeitos de sentidos da enunciação. A partir dessa referência, por conseguinte, as fronteiras entre o dizível e o não-dizível, o determinado e o indeterminado podem ser analisadas também através de diferentes formas de produção de transparência/opacidade no discurso.

c) O conceito de tensão, no espaço do dizível e do determinado ${ }^{5}$, produzse como um efeito do exercício de poder que, materializado nos enunciados, representa os lugares hegemônicos incorporados pela enunciação, os quais

\footnotetext{
${ }^{4}$ Reportamo-nos às análises das relações de intersubjetividade estabelecidas entre Blum e Thorez, como representantes dos partidos socialista e comunista francês, e os militantes da Frente Popular em maio de 1936.

${ }^{5}$ O termo "determinado" está sendo utilizado para descrever a intervenção de acontecimentos extraenunciativos (histórico-sociais) nas condições de produção dos sentidos, que, de acordo com Deleuze (1974), adquirem uma objetividade no espaço de coexistência do acontecimento e da estrutura.
} 
restringem, em maior ou menor grau, os espaços de intersubjetividade. Deste modo, quanto mais determinados os lugares da enunciação e mais expressivas as formas de representação do poder, maior a unilateralidade do discurso e mais evidentes os efeitos de anulação do lugar do outro.

d) Já o conceito de modalização remete às formas empíricas de produção da subjetividade do enunciador diante dos acontecimentos (invariantes projetadas no discurso) e dos enunciados. Este tipo de referência, que simboliza os traços de individualidade/identidade do enunciador, evidencia no interior dos enunciados índices lingüísticos que se reiteram e cujos efeitos permitem identificar ou caracterizar a enunciação.

Com o propósito de inter-relacionar as concepções de Courdesses com outras referências a respeito de enunciação e condições heterogêneas de representação na materialidade dos enunciados, passaremos, a seguir, à abordagem de considerações de Ducrot (1987) a respeito do tema.

Para Ducrot, um discurso não se constitui de uma seqüência linear de enunciados, onde cada escolha enunciativa independe de referências ao dizer do outro. Ao contrário, se o discurso pode ser caracterizado como um jogo de representações dos processos de enunciação nos enunciados, onde o dizer de um está sempre constituído pelo dizer de outro, os enunciados não podem ser unidades de investigação homogêneas, mas heterogêneas.

É, pois, a partir do pressuposto de que a enunciação pode ter vários sujeitos em sua origem que Ducrot redefine a propriedade de coesão discursiva ${ }^{6}$ como uma rede articulatória de enunciações, introduzindo, assim, o conceito de polifonia como um processo de representações heterogêneas do sujeito nas formulações enunciativas.

Deste modo, de acordo com o autor, é a propriedade de coesão que permite caracterizar a homogeneidade enunciativa como uma ilusão produzida na superfície dos enunciados, e a diversidade de representações de sujeitos como espaços de referências e partições enunciativas.

Entendendo, portanto, que um mesmo enunciado pode remeter a representações heterogêneas de enunciação, as quais configuram as condições de produção dos sentidos do discurso, o autor determina a funcionalidade dos sentidos como efeitos de condições de produção enunciativas que emergem das formas materiais dos enunciados.

A fim de descrever a funcionalidade do conceito, Ducrot desdobra o sujeito da enunciação em: a) um locutor (enunciador) que constrói o discurso, e ao qual se devem as condições de representação dos efeitos de sentidos veiculados por enunciações nos enunciados; b) um locutor que se representa como um ser a quem é imputada a responsabilidade da enunciação.

Assim, segundo o autor, se $\mathrm{X}$ enuncia $O$ dia está feio, através do discurso direto, $\mathrm{X}$ é ao mesmo tempo o locutor que produz a enunciação e se responsabiliza

${ }^{6}$ De forma distinta do conceito proposto por Halliday e Hasan (1976), Ducrot (1987) caracteriza o princípio de coesão a partir da enunciação e não dos enunciados.

82 
por ela. Mas se X diz que não acha que o dia está feio em Porto Alegre, identificase a presença de dois locutores: a) L1, que se configura como a origem da enunciação de L2; b) L2, que se apropria da enunciação de L1, reformulando seu sentido.

Por outro lado, se um sujeito $\mathrm{X}$ outorga a $\mathrm{Y}$ direitos de representação jurídica através de Procuração por Instrumento Público, mesmo ditando à instituição os tipos de poderes outorgados, este ainda configura-se como locutor, uma vez que responsabiliza-se apenas pelo ato de atribuição de poderes, dependendo da modalidade de enunciação do Tabelionato para legitimar-lhe as ações.

Da mesma forma, se o líder de um Partido Y informa à população que o Partido (enunciador) não afirmou $\mathrm{Z}$ mas $\mathrm{W}$, tem-se um processo de representação polifônica que compreende as seguintes partições enunciativas: a) a afirmação de $\mathrm{Z}$; b) a negação ou reformulação de Z; c) a afirmação de W.

É, portanto, com base em representações da heterogeneidade dos sujeitos que Ducrot define o papel do enunciador como responsável pelo enunciado, por oposição à responsabilidade de enunciação. Por esse prisma, o enunciador passa a ser caracterizado como aquele que dá existência, através dos enunciados, a enunciadores múltiplos, a partir dos quais ele organiza pontos de vista e posicionase diante de seus enunciados.

Finalmente, este tipo de relação dialética permite concluir que, para Ducrot, o processo de produção de sentidos na linguagem não equivale às práticas de representação dos mesmos.

\section{ANÁLISES}

Com base nos referenciais teóricos abordados, será analisada, a seguir, "A profecia de Aías contra Jeroboão"

"A profecia de Aías contra Jeroboão"

1 Naquele tempo adoeceu Abias, filho de Jeroboão.

2 Disse este a sua mulher: Dispõe-te agora, e disfarça-te

3 para que não conheçam que és mulher de Jeroboão e vai

4 a Silo. Eis que lá está o profeta Aías, o qual a meu

5 respeito disse que eu seria rei sobre este povo.

6 Leva contigo dez pães, bolos e uma botija de mel e

7 vai ter com ele; ele te dirá o que há de suceder a

8 este menino.

9 A mulher de Jeroboão assim o fez; levantou-se, foi a

10 Silo, e entrou na casa de Aías; Aías já não podia ver 
11 porque seus olhos já se tinham escurecido, por causa da 12 velhice.

13 Porém o Senhor disse a Aías: Eis que a mulher de Jeroboão 14 vem consultar-te sobre seu filho que está doente. Assim 15 e assim lhe falarás, porque ao entrar fingirá ser outra. 16 Ouvindo Aías o ruído de seus pés, quando ela entrava pela 17 porta, disse: Entra mulher de Jeroboão; por que finges 18 assim? Pois estou encarrregado de te dizer duras novas. 19 Vai dizer a Jeroboão: Assim diz o Senhor Deus de Israel: 20 Porquanto te levantei do meio do povo e te fiz príncipe 21 sobre o meu povo de Israel e tirei o reino da casa de 22 Davi, e to entreguei e tu não foste como Davi, meu servo, 23 que guardou os meus mandamentos após mim de todo o seu 24 coração para fazer somente o que parecia reto aos meus 25 olhos; antes fizeste outros deuses e imagens de fundição 26 para provocar-me à ira, e me viraste as costas.

27 Portanto, eis que trarei o mal sobre a casa de Jeroboão 28 e eliminarei todo e qualquer do sexo masculino, assim o 29 escravo como o livre, e lançarei fora os descendentes da 30 casa de Jeroboão, como se lança fora o esterco, até que 31 de todo ele se acabe.

32 Quem morrer a Jeroboão, na cidade os cães o comerão, e 33 quem morrer no campo aberto, as aves o comerão, porque 34 o Senhor o disse.

$35 \mathrm{Tu}$, pois, dispõe-te e vai para tua casa; quando puseres os 36 pés na cidade o menino morrerá. Todo o Israel o pranteará 37 e o sepultará; porque de Jeroboão só este dará 38 entrada em sepultura, porquanto se achou nele cousa boa 39 para com o Senhor Deus de Israel em casa de Jeroboão. 40 Que digo eu? Há de ser já.

41 Também o Senhor ferirá a Israel para que se agite como 42 a cana se agita nas águas; arrancará a Israel desta

43 boa terra que havia dado a seus pais, e o espalhará 44 para além do Eufrates, porquanto fez os seus postes-ídolos, 45 provocando o Senhor à ira.

46 Abandonará a Israel por causa dos pecados que Jeroboão 47 cometeu, e pelos que fez Israel cometer. 48 Então a mulher de Jeroboão se levantou, foi e chegou 49 a Tirza; chegando ela ao limiar da casa, morreu o menino. 50 Sepultaram-no e todo Israel o pranteou, segundo a palavra 51 do Senhor por intermédio do profeta Aías, seu servo. 52 Quanto aos mais atos de Jeroboão, como guerreou e como 53 reinou, eis que está escrito no livro da história dos 
54 reis de Israel.

A enunciação da profecia de Aías contra Jeroboão produz-se, inicialmente, sob a forma de um relato histórico em discurso indireto $(1 \mathrm{s.1}, 2)$ e introduz, através do recurso do discurso direto, simulações de enunciações históricas que podem ser caracterizadas como efeitos das condições de produção dos enunciados no discurso.

Pode-se observar que é através de um jogo de teatralização de vozes, configurado pela alternância dos estilos direto (ls.2,13,17,41), no presente, pretérito e futuro, e indireto no pretérito (ls.1,9,13), que se instauram as condições gerais de produção do processo de polifonia. Deste modo, enquanto a construção dos enunciados narrativos no pretérito remete aos acontecimentos históricos, a construção da dialogia, em várias modalidades temporais, produz um efeito de atualização dos fatos que aproxima locutores e enunciação, conforme os recortes abaixo.

a) efeitos de narração.

Naquele tempo adoeceu Abias, filho de Jeroboão. (1).

A mulher de Jeroboão assim o fez; levantou-se, foi a Silo, e entrou na casa de Aías... (ls.9,10). mulher).

b) efeitos de dialogia (recortes de diálogos de Jeroboão e Aías com a

Leva contigo dez pães, bolos e uma botija de mel e vai ter com ele; ele te dirá o que há de suceder a este menino. (1s.6,7,8).

Vai dizer a Jeroboão: Assim diz o Senhor Deus de Israel... (1.19).

Há que se observar que, se as utilizações dos estilos indireto e direto configuram-se também como índices de modalização, identificando, assim, os espaços de teatralização de vozes dos locutores, recursos formais de temporalidade, tais como desinências verbo-temporais de pretérito e a dêixis inicial (1.1) produzem efeitos de distanciamento do acontecimento histórico-discursivo.

Naquele tempo adoeceu Abias, filho de Jeroboão. Disse este a sua mulher: "Dispõe-te agora e disfarça-te..." (ls.1,2).

É, pois, através do recurso de construção de uma anacronia (naquele tempo) que a enunciação apaga as condições históricas de produção dos fatos discursivos, excluindo o leitor do processo de resgate de invariantes (históricosociais).

Esses efeitos de distanciamento, que se constituem pela oposição entre narrativas, dialogias e construções temporais, contribuem ainda para a inserção de determinados tipos de avaliações na narrativa, as quais revestem-se de um aparente prisma de neutralidade:

Aías já não podia ver porque seus olhos já se tinham escurecido, por causa da velhice. Porém o Senhor disse a Aías: Eis que a mulher de Jeroboão vem consultar-te sobre seu filho... Assim e assim lhe falarás...

Conforme pode-se observar acima, é por meio de um efeito de 
distanciamento que são inseridas na narrativa avaliações, para o leitor, sobre os sentidos sensoriais e extra-sensoriais do profeta Aías. E, desta forma, o narrador passa a converter-se em testemunha, aparentemente neutra, dos seguintes fatos: a) o profeta Aías não teria condições de reconhecer alguém através do sentido visual; b) o mesmo possuía uma espécie de sensorialidade auditiva fora dos padrões comuns.

Por outro lado, na mesma proporção em que as construções enunciativas do discurso opõem narrativa histórica e locuções, institucionalizam e constituem, através do recurso da polifonia, condições objetivas de resgate dos tipos de relações hegemônicas dominantes entre as tribos de Israel.

A fim de que possam ser identificados determinados tipos de relações estabelecidas entre as enunciações e as representações simbólicas das condições de funcionamento das escalas hegemônicas das tribos israelenses, passaremos a analisar, a seguir, sequiências enunciativas construídas pelo discurso. E, sob uma perspectiva metodológica, a simbologia abaixo será utilizada como uma possibilidade de descrição das condições de formulação dos enunciados, conforme o quadro de equivalências que segue:

Senhor $\Rightarrow(S)$, Aías $\Rightarrow(A)$, Mulher $\Rightarrow(M)$, Narrador $\Rightarrow(N)$, Jeroboão $\Rightarrow$ $(\mathrm{J})$, Povo de Israel $\Rightarrow(\mathrm{P})$.

Deste modo, com base em representações de enunciações polifônicas inscritas nos enunciados, serão analisadas as condições de funcionamento dos sentidos que permeiam o quadro histórico-simbólico da sociedade judaica.

Inicialmente, faz-se possível observar, através dos enunciados, um paralelismo discursivo que estabelece relações de distanciamento entre o rei de Israel e o Ser Supremo. Isto é, o Senhor (S) fala a Aías (A), constituindo-o seu porta-voz frente a Jeroboão (J), para veicular duas profecias: a) Jeroboão será o rei das tribos de Israel; b) todos os descendentes de Jeroboão serão eliminados e destruídos, por este ter descumprido as doutrinas religiosas ${ }^{7}$. Já o rei fala à mulher, designando-a como porta-voz no processo de resolução de seus problemas. Por fim, o diálogo entre o Ser Supremo e Jeroboão, representado na concretude dos enunciados por paralelismos, é realizado através das medições de Aías e da esposa de Jeroboão.

Conforme pode-se observar, a seguir, as partições dos enunciados que representam os processos de inscrição do dizer de um no dizer de outro, demonstram que as mensagens do rei e para o rei nunca são objetos de interlocução direta.

(1) Representação da enunciação de Aías no diálogo de Jeroboão Eis que lá está o profeta Aías,

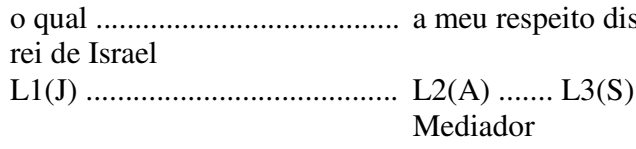

\footnotetext{
${ }^{7}$ A profecia reporta ao fato histórico de Jeroboão ter erguido estátuas a vários deuses, contrariando, assim, os princípios monoteístas.
} 
(2) Representação da enunciação de Jeroboão no diálogo do Senhor com Aías

Eis que a mulher de Jeroboão vem consultar-te sobre

seu filho...

L1 (S)

Assim e assim lhe falarás

porque ao entrar fingirá ser outra

L1 (S) L2 (M) L3 (J)

(3) Representação da enunciação do Senhor no diálogo de Aías com a mulher

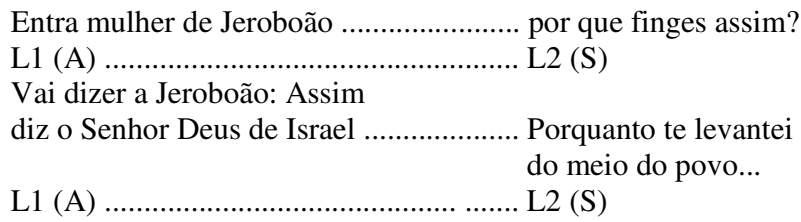

As partições dos enunciados acima elucidam o fato de que as condições de funcionamento das relações de interlocução entre os representantes maiores das tribos são sempre mediadas pela presença de um porta-voz, razão pela qual as enunciações do Senhor (S) e de Jeroboão (J) inscrevem-se em outras enunciações.

Há que se destacar, por outro lado, o fato de que a inscrição do dizer da mulher no dizer de outros é apenas representada simbolicamente, e tal fato demonstra a existência de um espaço lacunar no discurso; isto é, um lugar não marcado formalmente, que permite o resgate da expressão de hegemonia entre o povo judaico.

Desta forma, enquanto as relações de articulação entre as enunciações permitem evidenciar que, enquanto: a) o Senhor dirige a palavra à Jeroboão (J) através de Aías (A); b) Jeroboão (J) referenda na profecia de Aías a fala do Senhor (S); c) Aías referenda a fala do Senhor (S) em seu diálogo com a mulher (M), a fim de cumprir determinações do Ser Supremo; a mulher nunca chega a constituir-se como locutora, sendo o seu papel reduzido apenas à condição de interlocutora de todos. Ou seja, cabe à mulher escutar, mediar interlocuções, sem, no entanto, intervir nas relações de intersubjetividade entre os demais, conforme atestam as enunciações abaixo.

(4) Representação de enunciações dirigidas à mulher

Por Jeroboão

Dispõe-te agora, e disfarça-te

para que não conheçam que és mulher de Jeroboão

L1 (J) L2 (P)

Pelo Senhor

Assim e assim lhe falarás

porque ao entrar fingirá ser outra

L1 (S) L2 (M) ....... L3 (J)

Enunciação lacunar

Por Aías 
Enunciação lacunar

Faz-se necessário observar ainda que é o próprio jogo de distanciamento entre as representações narrativas e dialógicas que instaura as relações de tensão no discurso, configurando, portanto, os efeitos de irreversibilidade do cumprimento da profecia de Aías contra Jeroboão. Tal fato pode ser confirmado ao término da profecia, através da retomada da enunciação do narrador, que reitera mais uma vez o testemunho do cumprimento das prospecções do profeta.

Então a mulher de Jeroboão se levantou, foi e chegou a Tirza; chegando ela ao limiar da casa, morreu o menino. Sepultaram-no e todo o Israel o pranteou, segundo a palavra do Senhor, por intermédio do profeta Aías, seu servo.

\section{CONCLUSÃO}

Com base nas análises das formas de representação das enunciações na profecia, pode-se resgatar, em última instância, o quadro histórico-hegemônico que explica as condições de formação do juridismo entre a sociedade judaica:

a) o lugar de maior hegemonia atribuído a um ser único e absoluto, representado, na prática religiosa, pela adoção do monoteísmo;

b) o lugar de mediação e sustenção das injunções do juridismo religioso sobre os demais, atribuído ao profeta, que representa na concretude das práticas sociais os efeitos de sobredeterminação do sujeito de religião sobre as demais jurisdições;

c) o papel de governar as tribos (sujeito de legislação) representado pelo sistema de monarquia ${ }^{8}$, cuja sustentação depende das injunções do sistema religioso;

d) os poderes de ação dos membros das tribos determinados, em primeiro lugar, pela jurisdição religiosa, e, a seguir, pela jurisdição monárquica;

e) a representação do lugar da figura feminina simbolizada por condutas de passividade, obediência e silêncio.

Finalmente, a partir das considerações já realizadas, pode-se concluir que as condições de institucionalização dos sentidos que explicam as práticas sociais entre o povo judaico são originadas do juridismo religioso. Deste modo, o lugar simbólico da autoridade entre o povo é transcendental, e os efeitos dessa lógica mística é que determinam as relações de transição do poder entre a sociedade.

\footnotetext{
${ }^{8}$ Reportamo-nos também às considerações de Baruch Spinoza (1994), que estabelece paralelismos entre os sistemas totalitarista, monárquico e o monoteísmo.
} 


\section{BIBLIOGRAFIA}

A BÍBLIA SAGRADA. Trad. João Ferreira de Almeida. Rio de Janeiro, Sociedade Bíblica do Brasil, p.377-78, 1960.

BENVENISTE, Emile. Problemas de lingüística geral II. Campinas, Pontes, 1989.

COURDESSES, Lucile. Blum et Thorez en mai 1936: analyses d'enoncés. Langue française, Paris, Larousse, v.9, p.23-33, 1971.

DUBOIS, Jean. Enoncé et énonciation. Langages, Paris, Didier/Larousse, v.13, p.101-110, 1969.

DELEUZE, Gilles. Lógica do sentido. São Paulo, Perspectiva, 1974.

DUCROT, Oswald. O dizer e o dito. Campinas, Pontes, 1987.

GUIMARÃES, Eduardo. Enunciação, polifonia e argumentação. In: . Texto e argumentação. Campinas, Pontes, 1987.

HALliDAY, M. A. K.; HASAN, R. Cohesion in English. London, Longman, 1976.

SPINOZA, Benedictus de. Tratado político. São Paulo, Ícone, 1994.

YAGUELLO, Marina. Bakhtin, o homem e seu duplo. In: BAKHTIN, Mikhail. Marxismo e filosofia da linguagem. São Paulo, Hucitec, 1986. 
